\title{
Intravenous Iron Therapy in Patients with Iron Deficiency Anemia: Dosing Considerations
}

\author{
Todd A. Koch, ${ }^{1}$ Jennifer Myers, ${ }^{2}$ and Lawrence Tim Goodnough ${ }^{3}$ \\ ${ }^{1}$ Luitpold Pharmaceuticals, Inc., Norristown, PA 19403, USA \\ ${ }^{2}$ St. John's University, Jamaica, NY 11439, USA \\ ${ }^{3}$ Department of Pathology and Medicine (Hematology), Stanford, CA 94305, USA
}

Correspondence should be addressed to Lawrence Tim Goodnough; ltgoodno@stanford.edu

Received 6 May 2015; Revised 18 June 2015; Accepted 23 June 2015

Academic Editor: Bruno Annibale

Copyright (C) 2015 Todd A. Koch et al. This is an open access article distributed under the Creative Commons Attribution License, which permits unrestricted use, distribution, and reproduction in any medium, provided the original work is properly cited.

\begin{abstract}
Objective. To provide clinicians with evidence-based guidance for iron therapy dosing in patients with iron deficiency anemia (IDA), we conducted a study examining the benefits of a higher cumulative dose of intravenous (IV) iron than what is typically administered. Methods. We first individually analyzed 5 clinical studies, averaging the total iron deficit across all patients utilizing a modified Ganzoni formula; we then similarly analyzed 2 larger clinical studies. For the second of the larger studies (Study 7), we also compared the efficacy and retreatment requirements of a cumulative dose of $1500 \mathrm{mg}$ ferric carboxymaltose (FCM) to $1000 \mathrm{mg}$ iron sucrose (IS). Results. The average iron deficit was calculated to be $1531 \mathrm{mg}$ for patients in Studies 1-5 and $1392 \mathrm{mg}$ for patients in Studies 6-7. The percentage of patients who were retreated with IV iron between Days 56 and 90 was significantly $(p<0.001)$ lower (5.6\%) in the $1500 \mathrm{mg}$ group, compared to the $1000 \mathrm{mg}$ group (11.1\%). Conclusions. Our data suggests that a total cumulative dose of $1000 \mathrm{mg}$ of IV iron may be insufficient for iron repletion in a majority of patients with IDA and a dose of $1500 \mathrm{mg}$ is closer to the actual iron deficit in these patients.
\end{abstract}

\section{Introduction}

Iron is an essential element and its balance must be maintained for proper physiologic functioning. Blood loss, a major cause of iron deficiency, is highly prevalent (e.g., females with menses and patients with chronic occult gastrointestinal (GI) blood loss) and requires proper diagnosis and management [1-4]. Therapeutic management of IDA is focused primarily on repletion of iron stores [1-4]. While iron deficient individuals without inflammation may respond to oral iron therapy, administration of IV iron is beneficial in many patient populations, including those with inflammation (resulting, e.g., from kidney disease, heart failure, or rheumatological diseases), patients who cannot tolerate oral iron, and patients who are noncompliant with oral iron therapy [5-8]. Even under the best of circumstances, oral iron is not well tolerated, and patients are often nonadherent for a variety of reasons, including intolerable side effects and the need for multiple daily doses [9]. The frequently poor absorption of oral iron, moreover, can contribute to suboptimal patient response.
The hepcidin response in anemic patients having inflammatory conditions, such as inflammatory bowel disease (IBD), inhibits GI absorption of oral iron [10]. Moreover, hepcidin impacts iron homeostasis in patients with concurrent inflammation (e.g., repressed recycling of iron from the reticuloendothelial system and sequestration in bone marrow); this may limit both oral and IV iron supplementation and may serve to explain why such patients remain iron deficient despite multiple courses of therapy $[6,10,11]$.

Cancer-related anemia (CRA) has multiple etiologies, including chemotherapy-induced myelosuppression, blood loss, functional iron deficiency, erythropoietin deficiency due to renal disease, and marrow involvement with tumor, among others. The most common treatment options for CRA include iron therapy, erythropoietic-stimulating agents (ESAs), and red cell transfusion. Safety concerns as well as restrictions and reimbursement issues surrounding ESA therapy for CRA have resulted in suboptimal treatment. Many believe that more routine use of IV iron for CRA and chemotherapyinduced anemia (CIA) is appropriate in view of existing 
TABLE 1: Potential role of iron therapy in management of anemia [12].

\begin{tabular}{|c|c|c|c|c|}
\hline Condition & $\begin{array}{c}\text { Expected } \\
\text { hepcidin levels }\end{array}$ & Iron parameters & Iron therapy strategies & $\begin{array}{c}\text { Potential hepcidin } \\
\text { therapy }\end{array}$ \\
\hline $\begin{array}{l}\text { Absolute iron deficiency } \\
\text { anemia (IDA) }\end{array}$ & Low & Low TSAT and ferritin & $\begin{array}{c}\text { PO or IV if poorly } \\
\text { tolerated or malabsorbed }\end{array}$ & No \\
\hline $\begin{array}{l}\text { Functional iron deficiency } \\
\text { (ESA therapy, CKD) }\end{array}$ & $\begin{array}{c}\text { Variable, } \\
\text { depending on } \\
\pm \mathrm{CKD} \\
\end{array}$ & $\begin{array}{l}\text { Low TSAT, variable } \\
\text { ferritin }\end{array}$ & ( & $\begin{array}{l}\text { Antagonist (if hepcidin } \\
\text { levels are not low) }\end{array}$ \\
\hline $\begin{array}{l}\text { Iron sequestration (anemia } \\
\text { of inflammation }(\mathrm{AI}) \text { ) }\end{array}$ & High & $\begin{array}{c}\text { Low TSAT, } \\
\text { normal-to-elevated } \\
\text { ferritin } \\
\end{array}$ & IV & Antagonist \\
\hline $\begin{array}{l}\text { Mixed anemia (AI/IDA or } \\
\text { AI/functional iron } \\
\text { deficiency) }\end{array}$ & Variable & $\begin{array}{c}\text { Low TSAT, } \\
\text { low-to-normal ferritin }\end{array}$ & $\mathrm{IV}^{*}$ & $\begin{array}{c}\text { Antagonist } \\
\text { (if hepcidin levels are } \\
\text { not low) }\end{array}$ \\
\hline
\end{tabular}

TSAT = transferrin saturation; $\mathrm{PO}=$ oral; IV = intravenous; $\mathrm{CKD}=$ chronic kidney disease; $\mathrm{ESA}$ = erythropoiesis-stimulating agent.

${ }^{*}$ Mixed anemia is a diagnosis of exclusion without a therapeutic trial of iron.

From [12].

evidence. Oncology patients whose CIA is treated with ESAs, furthermore, respond better to IV iron therapy than to oral supplementation [7, 13-19].

Table 1 illustrates various conditions where IV iron therapy may be warranted.

Despite beneficial effects in a wide range of patients, administration of IV iron may generate oxidative stress and other inflammatory changes, and the risk-benefit profile of IV iron continues to undergo evaluation in renal dialysis patients $[20,21]$, as well as patients with anemia due to other chronic diseases [22]. The long-term effects of IV iron preparations will require further study in relevant clinical settings, [23] as will the long-term deleterious effects of allogeneic blood transfusions [24-26].

IV iron preparations currently approved in the US are listed in Table $2[8,10,27-36]$. Beginning with the first iron dextran product introduced, the recommended cumulative replacement dose for many of these products has been approximately $1000 \mathrm{mg}$ of iron [29-35].

A patient's total body iron deficit can be calculated using the Ganzoni formula (total iron dose $=[$ actual body weight $\times$ $(15$-actual $\mathrm{Hb})] \times 2.4+$ iron stores) [32]. Because many view this formula as inconvenient, it is not consistently used in clinical practice [37]. Although use of the Ganzoni formula is ideally the best way to select dose, it is impractical, partly because product labels state specific dosing regimens. In typical clinical practice, doses are more efficiently chosen based on approved product labels and local protocols, and only in the Dexferrum (iron dextran injection, USP) and INFeD (iron dextran injection, USP) prescribing information is a weight and $\mathrm{Hb}$-based table available to calculate a patient's total iron requirement utilizing similar formula. There are also only a limited number of clinical practice guidelines regarding the use of a total cumulative repletion dose of IV iron in IDA patients, and, as mentioned above, the FDAapproved labeling for many IV iron products recommends a total cumulative dose of approximately $1000 \mathrm{mg}$. Currently, there is no consensus regarding the most appropriate iron deficit repletion dosing in patients with IDA, partly because the iron dosing selected for virtually all trials has been based largely on clinical judgment, clinical guidelines in nephrology, or best estimates from past results. In this retrospective study, we systematically explored the iron deficit in patients who received IV iron in clinical studies and examined the potential benefits (i.e., normalization of $\mathrm{Hb}$ and time to retreatment with IV iron) of a higher cumulative dose of IV iron than what is typically administered, with the goal of providing clinicians with practical, evidence-based guidance for determining iron dosing requirements in a wide range of patients with IDA.

\section{Materials and Methods}

In this study, we used the same population recruited from previous clinical trials [38-44]. These studies adhered to US federal regulations and were performed in accordance with the Declaration of Helsinki and lastly protocols and informed consent forms were approved by local or national institutional review boards. All participants in these studies provided written informed consent. Patient records/information were anonymized and deidentified prior to analysis.

In Studies 1-5 (summarized below), each patient's iron deficit (mg) had been originally calculated and dose of iron administered, according to a modified Ganzoni formula: subject weight in $\mathrm{kg} \times[15$-current $\mathrm{Hb} \mathrm{g} / \mathrm{dL}] \times 2.4+500$, as specified in each study protocol. The Ganzoni formula had been modified for use in these studies to help alleviate any potential for iron overload in subjects who had a transferrin saturation $($ TSAT) $>20 \%$ and ferritin $>50 \mathrm{ng} / \mathrm{mL}$ at study entry. For these subjects, a conservative estimate was made, and the additional $500 \mathrm{mg}$ from the formula to replete iron stores was not added to the total iron requirement. Each study administered IV iron (ferric carboxymaltose, FCM) as a total cumulative dose to randomized patients based upon the iron deficit so calculated. In analyzing each study, we utilized the baseline iron deficits for each patient using the same method and then averaged the total iron deficit across patients. These clinical studies examined IDA in postpartum 


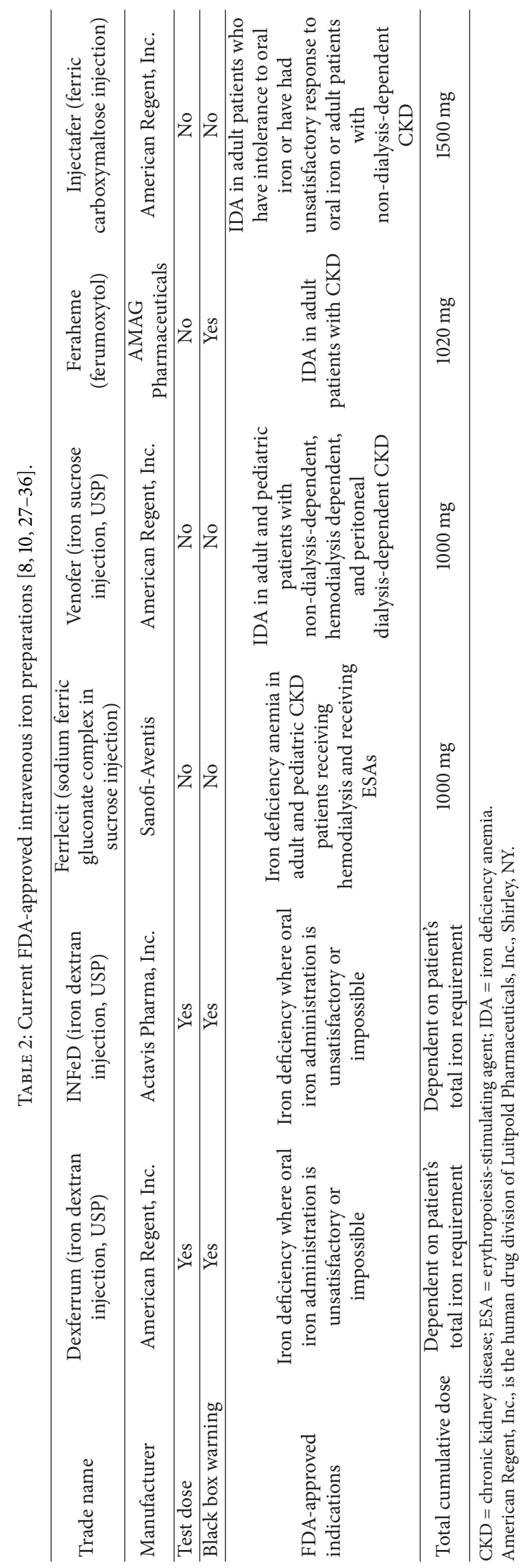


TABLE 3: Average calculated iron deficit dose in clinical Studies 1-5.

\begin{tabular}{lcccc}
\hline Study & Patient population & $\begin{array}{c}\text { Calculated mean iron deficit based } \\
\text { on the modified Ganzoni formula* } \\
\text { (mg) }\end{array}$ & $\begin{array}{c}\text { Standard } \\
\text { deviation }\end{array}$ & $\begin{array}{c}\text { Number of } \\
\text { patients }\end{array}$ \\
\hline (1) van Wyck et al., 2007 [38] & Postpartum & 1458 & 330 \\
(2) van Wyck et al., 2009 [39] & Heavy uterine bleeding & 1608 & 383 & 182 \\
(3) Seid et al., 2008 [40] & Postpartum & 1539 & 351 & 342 \\
(4) Barish et al., 2012 [41] & IDA various etiologies & 1520 & 359 & 143 \\
(5) Hussain et al., 2013 [42] & IDA various etiologies & $1508^{* *}$ & NC & 161 \\
Overall mean & & 1531 & 1085 \\
\hline
\end{tabular}

IDA = iron deficiency anemia; NC = not calculated.

${ }^{*}$ Patients randomized to receive IV iron based on a calculated iron deficit.

** Including all randomized patients.

Data on file, Luitpold Pharmaceuticals, Inc.

patients, patients with heavy uterine bleeding (HUB), nondialysis-dependent chronic kidney disease (NDD-CKD), GI disorders, and other underlying conditions.

Following are short descriptions of each study:

(1) Comparison of the safety and efficacy of IV iron (FCM) and oral iron (ferrous sulfate) in patients with postpartum anemia $(N=361)$ [38], NCT00396292.

(2) Comparison of the safety and efficacy of IV iron (FCM) and oral iron (ferrous sulfate) in the treatment of IDA secondary to HUB $(N=477)$ [39], NCT00395993.

(3) Comparison of the safety and efficacy of IV iron (FCM) and oral iron (ferrous sulfate) in the treatment of postpartum patients $(N=291)$ [40], NCT00354484.

(4) Comparison of the safety and tolerability of IV iron (FCM) and standard medical care (oral and IV iron) in treating IDA of various etiologies $(N=708)$ [41], NCT00703937.

(5) Comparison of the safety and tolerability of IV iron (FCM) and iron dextran in treating IDA of various etiologies $(N=160)$ [42], NCT00704028.

Following review of Studies 1-5, two larger studies (6 and 7) that utilized $1500 \mathrm{mg}$ IV iron (as specified in the protocols) were examined. Although the modified Ganzoni formula was not specified in the protocols to determine dose requirements in these 2 studies, we did apply the formula to determine each patient's baseline iron deficit in a separate retrospective post hoc analysis of each study. We then averaged the total iron deficit across patients. Additionally, Study 7 compared the safety and efficacy of $1500 \mathrm{mg}$ of IV iron (as FCM) to $1000 \mathrm{mg}$ of IV iron (as iron sucrose [IS]) examining any potential efficacy or safety difference between the two dosing regimens.

A short summary of Studies 6 and 7 follows:

(6) Comparison of $1500 \mathrm{mg}$ IV iron (FCM) with oral iron and IV iron standard of care (SoC) therapy (as determined by the investigator) in patients with IDA of various etiologies who had an unsatisfactory response to oral iron or were deemed inappropriate for oral iron [43], NCT00982007.

(7) Comparison of the safety and efficacy of $1500 \mathrm{mg}$ (FCM) to $1000 \mathrm{mg}$ of IV iron (IS) in patients with IDA and NDD-CKD [44], NCT00981045.

Statistical Analysis. Baseline iron deficits in each clinical study were calculated for all subjects who were randomized to receive IV iron. In Study 5 [42], iron deficits were calculated for all subjects, as the comparator (iron dextran) was also dosed based on the modified Ganzoni formula and was summarized with descriptive statistics. For the iron deficit calculations performed for Studies 6 and 7, all subjects in the Safety Population were included. The iron deficits were averaged and the standard deviation was generated.

For Study 7, the Safety Population consisted of all subjects who received a dose of randomized treatment. The intent-totreat (ITT) population for evaluating all efficacy endpoints consisted of all subjects from the Safety Population who received at least 1 dose of randomized study medication and had at least 1 postbaseline $\mathrm{Hb}$ assessment. Treatment assignments were analyzed according to the actual treatment received. The differences between $1500 \mathrm{mg}$ and $1000 \mathrm{mg}$ for time-to-event variables in Study 7 were assessed with the point estimate and $95 \%$ CI for the hazard ratio calculated from a Cox proportional hazards model. Treatment group differences were assessed using the Cox proportional hazards model with treatment as a fixed factor. In addition, $p$ values for treatment differences were provided from the log-rank test. Time-to-event variables are displayed descriptively as Kaplan-Meier curves.

All statistical tests were post hoc with no adjustment to type I error for multiple comparisons.

\section{Results}

The average total iron deficits for patients in the 7 cited trials are summarized in Tables 3 and 4 . The overall average total iron deficit in the initial 5 clinical trials was $1531 \mathrm{mg}$ (Table 3). Total iron requirements among patients in each cohort in Studies 6 and 7 are summarized in Table 4. In Study 6, the average calculated iron deficit (Cohorts 1 and 2) was $1496 \mathrm{mg}$. 


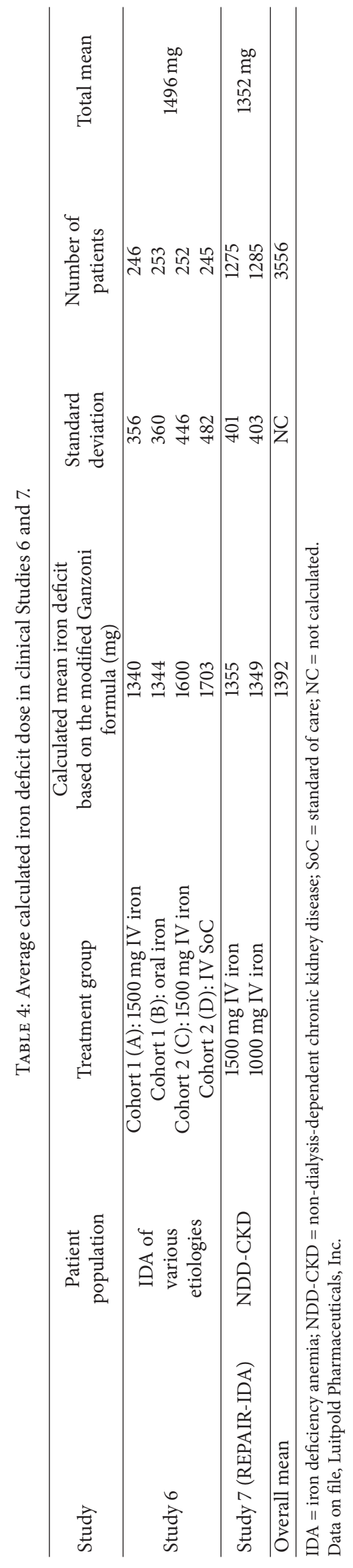


TAble 5: Retreatment between Days 56-90 in clinical Study 7 (Safety Population).

\begin{tabular}{lccc}
\hline & $1500 \mathrm{mg}$ IV iron $(n=1276)$ & $1000 \mathrm{mg}$ IV iron $(n=1285)$ & $p$ value \\
\hline$N(\%)$ patients retreated & $71(5.6 \%)$ & $142(11.1 \%)$ & $p<0.001$ \\
\hline
\end{tabular}

Data on file, Luitpold Pharmaceuticals, Inc.

TABLE 6: $\mathrm{Hb}>12 \mathrm{~g} / \mathrm{dL}$ and end of treatment (Day 56) from clinical Study 7 (ITT population).

\begin{tabular}{cccc}
\hline & $1500 \mathrm{mg}$ IV iron $(n=1249)$ & $1000 \mathrm{mg}$ IV iron $(n=1244)$ & $p$ value \\
\hline$N(\%)$ patients with $\mathrm{Hb}>12.0 \mathrm{~g} / \mathrm{dL}$ & $265(24.4 \%)$ & $169(15.6 \%)$ & $p=0.001$ \\
\hline
\end{tabular}

$\mathrm{Hb}=$ hemoglobin; ITT $=$ intent-to-treat.

Data on file, Luitpold Pharmaceuticals, Inc.

TABLe 7: Subjects with $\mathrm{Hb}>11 \mathrm{~g} / \mathrm{dL}, 12 \mathrm{~g} / \mathrm{dL}$, or $\mathrm{Hb}$ change $\geq 1 \mathrm{~g} / \mathrm{dL}$ in Study 7 anytime from randomization to end of study (Safety Population).

\begin{tabular}{lccc}
\hline & $1500 \mathrm{mg}$ IV iron $(n=1276)$ & $1000 \mathrm{mg}$ IV iron $(n=1244)$ & Hazard ratio $(95 \%$ CI $)$ \\
\hline$N(\%)$ of patients with $\mathrm{Hb}>11 \mathrm{~g} / \mathrm{dL}$ & $557(56.1 \%)$ & $504(51.1 \%)$ & $1.15(1.02-1.30)$ \\
$N(\%)$ of patients with $\mathrm{Hb}>12 \mathrm{~g} / \mathrm{dL}$ & $358(28.6 \%)$ & $251(20.0 \%)$ & $1.44(1.23-1.70)$ \\
$N(\%)$ of patients with $\mathrm{Hb}$ change $\geq 1 \mathrm{~g} / \mathrm{dL}$ & $610(48.7 \%)$ & $513(41.0 \%)$ & $1.27(1.13-1.43)$ \\
\hline
\end{tabular}

$\mathrm{Hb}=$ hemoglobin.

Data on file, Luitpold Pharmaceuticals, Inc.

In Study 7 , the average calculated iron deficit for patients receiving either $1500 \mathrm{mg}$ or $1000 \mathrm{mg}$ was $1352 \mathrm{mg}$. Overall, the average total iron deficit for clinical Studies 6 and 7 was $1392 \mathrm{mg}$.

In Study 7, study participants were randomized to receive either two $750 \mathrm{mg}$ doses of IV iron (FCM) 7 days apart or IS $200 \mathrm{mg}$ administered in up to 5 infusions over 14 days. The primary efficacy endpoint was the mean change in $\mathrm{Hb}$ from baseline to highest reported $\mathrm{Hb}$ (from baseline to Day 56). Patients were followed up for safety to Day 120 . The mean total dose of iron received was $1464 \mathrm{mg}$ in the $1500 \mathrm{mg}$ group and $963 \mathrm{mg}$ in the $1000 \mathrm{mg}$ group. Mean baseline $\mathrm{Hb}$ values were $10.31 \mathrm{~g} / \mathrm{dL}$ for the $1500 \mathrm{mg}$ group and $10.32 \mathrm{~g} / \mathrm{dL}$ for the $1000 \mathrm{mg}$ group.

In this study, the mean increase in $\mathrm{Hb}$ overall was $1.13 \mathrm{~g} / \mathrm{dL}$ in the $1500 \mathrm{mg}$ group and $0.92 \mathrm{~g} / \mathrm{dL}$ in the $1000 \mathrm{mg}$ group (95\% CI, 0.13-0.28), meeting the prespecified endpoint of noninferiority of $1500 \mathrm{mg}$ to $1000 \mathrm{mg}$. Additionally, as evidenced by the $95 \%$ CI not including $0,1500 \mathrm{mg}$ was superior to $1000 \mathrm{mg}$ in increasing $\mathrm{Hb}$.

The proportion of patients in the $1500 \mathrm{mg}$ group who were retreated with IV iron between Days 56 and 90 (Safety Population) was significantly $(p<0.001)$ lower, $71 / 1276(5.6 \%)$, than the $142 / 1285$ (11.1\%) patients who required retreatment in the $1000 \mathrm{mg}$ group (Table 5). Figure 1 displays the time from Day 56 to additional IV iron when comparing $1500 \mathrm{mg}$ to $1000 \mathrm{mg}$.

Post hoc analyses of patients with $\mathrm{Hb}>12 \mathrm{~g} / \mathrm{dL}$ at end of treatment (Day 56) and time to first $\mathrm{Hb}>11 \mathrm{~g} / \mathrm{dL}$ and $>12 \mathrm{~g} / \mathrm{dL}$ and $\mathrm{Hb}$ increase $\geq 1 \mathrm{~g} / \mathrm{dL}$ were conducted. The proportion of patients with $\mathrm{Hb}>12 \mathrm{~g} / \mathrm{dL}$ at the end of treatment (baseline to Day 56) was $265 / 1249$ in the $1500 \mathrm{mg}$ group (24.4\%) and $169 / 1244$ in the $1000 \mathrm{mg}$ group (15.6\%), $p=0.001$ (Table 6).

Patients who received $1500 \mathrm{mg}$ IV iron were also more likely to achieve $\mathrm{Hb}>11 \mathrm{~g} / \mathrm{dL}, \mathrm{Hb}>12 \mathrm{~g} / \mathrm{dL}$, or an increase in $\mathrm{Hb} \geq 1 \mathrm{~g} / \mathrm{dL}$ compared with those receiving $1000 \mathrm{mg}$ (Table 7).

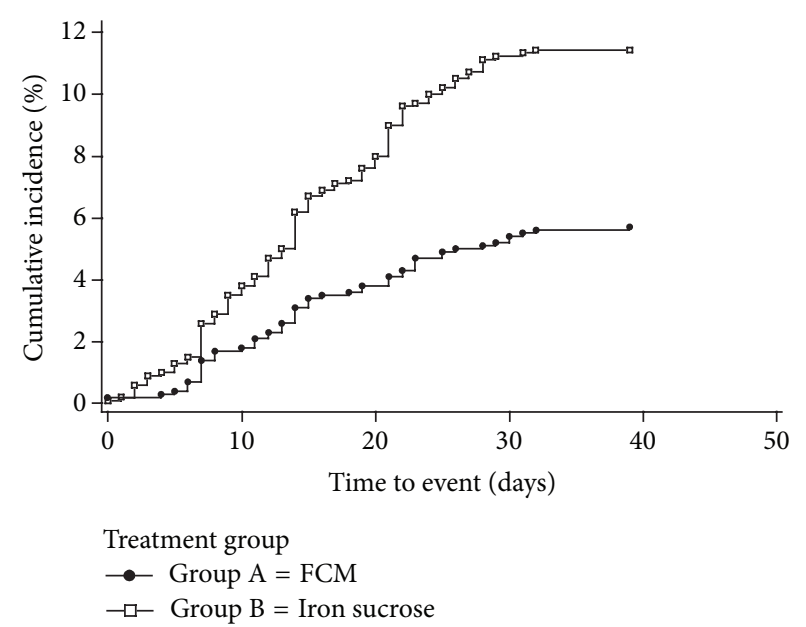

FIgURE 1: The time to additional intravenous (IV) iron after Day 56 comparing $1500 \mathrm{mg}$ to $1000 \mathrm{mg}$ IV iron in the Safety Population of Study 7. Data on file, Luitpold Pharmaceuticals, Inc.

Furthermore, the times to first $\mathrm{Hb}>11 \mathrm{~g} / \mathrm{dL}$ and $>12 \mathrm{~g} / \mathrm{dL}$ and to $\mathrm{Hb}$ increases $\geq 1 \mathrm{~g} / \mathrm{dL}$ were all statistically significantly shorter for the $1500 \mathrm{mg}$ group than for the $1000 \mathrm{mg}$ group $(p=0.013, p<0.001$, and $p<0.001$, resp.). Figure 2 presents the Kaplan-Meier analysis for time to first $\mathrm{Hb}$ $>12 \mathrm{~g} / \mathrm{dL}$.

The $1500 \mathrm{mg}$ total cumulative dose had a similar safety profile to that of $1000 \mathrm{mg}$ of IS, demonstrating that $50 \%$ more iron in the form of FCM can be administered while maintaining a safety profile comparable to that of IS [44].

\section{Discussion}

In the US, it has become common practice to administer a cumulative dose of approximately $1000 \mathrm{mg}$ of IV iron (in 


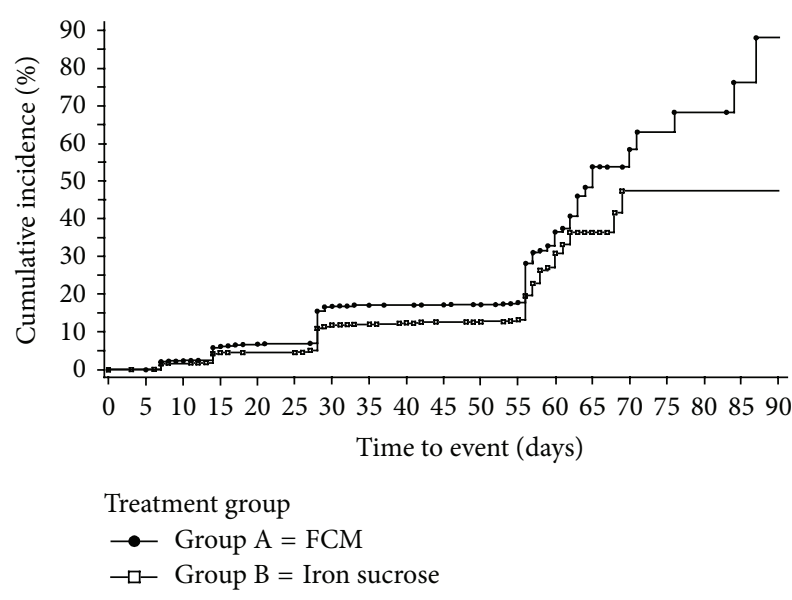

FIGURE 2: The time from randomization to first hemoglobin $>12 \mathrm{~g} / \mathrm{dL}$ in patients who received $1500 \mathrm{mg}$ IV iron and patients who received $1000 \mathrm{mg}$ from Study 7, $p<0.001$. Day 56 is the last study visit, and at the discretion of the investigator, patients were allowed to be retreated with additional IV iron between Days 56 and 90. Data on file, Luitpold Pharmaceuticals, Inc.

divided doses) for the treatment of IDA. This is due, in large part, to the use of IV iron in nephrology. Both the Kidney Disease Outcomes Quality Initiative (KDOQI), initially developed in 1996, and the more recent Kidney Disease: Improving Global Outcomes (KDIGO) practice guidelines provide recommendations for the treatment of IDA utilizing IV iron. In the randomized controlled trials reviewed to develop the guidelines, a cumulative dose of $1000 \mathrm{mg}$ of IV iron was utilized $[45,46]$. Although that has now become the standard therapeutic dose for iron deficiency of various etiologies in light of a wealth of safety and efficacy data, it may not provide repletion of iron that is sufficient to alleviate the iron deficient state, thereby necessitating retreatment or creating the potential for a subtherapeutic response.

Despite these recommendations, in many clinical situations the treatment of IDA with IV iron has not been limited to a cumulative dose of $1000 \mathrm{mg}$. In oncology patients, for example, the National Comprehensive Cancer Network (NCCN) states that if the calculated dose exceeds $1000 \mathrm{mg}$, the remaining dose may be given after 4 weeks if the $\mathrm{Hb}$ response is inadequate [47].

Additionally, in two randomized controlled trials involving IV iron supplementation in oncology patients, a total of up to $3000 \mathrm{mg}$ iron was administered in weekly doses of $100 \mathrm{mg}$ [48]. In another prospective, randomized, controlled trial, patients with chemotherapy-related anemia received cumulative doses of IV iron ranging from 1000 to $3000 \mathrm{mg}$ [7].

Guidelines for the management of IDA in inflammatory bowel disease (IBD), moreover, recommend IV iron as the preferred route of administration and state that anemic IBD patients rarely present with total iron deficits below $1000 \mathrm{mg}$. These guidelines recommend use of the Ganzoni formula to estimate iron replacement needs, and in controlled trials, up to $3600 \mathrm{mg}$ of iron sucrose has been administered safely (up to TSAT >50\%) [49]. A 2011 review by Gozzard [50] further highlights numerous clinical situations requiring doses of IV iron above a cumulative dose of $1000 \mathrm{mg}$. Congruent with evidence reported in the international IBD guidelines, the article states that cumulative doses up to $3600 \mathrm{mg}$ of IV iron may be administered safely in these patients. The review also suggests that higher doses of IV iron may overcome impaired iron absorption associated with hepcidin blockade in this patient population. In another multiple-dose, phase II/III study of IDA patients with GI disorders, mean total cumulative doses of $1800 \mathrm{mg}$ IV iron were administered [51]. Clinical evidence also indicates that iron requirements of 1000 to $1500 \mathrm{mg}$ or higher may be required in patients with NDD-CKD to attain target ferritin and $\mathrm{Hb}$ levels, up to $1600 \mathrm{mg}$ may be required in obstetric patients, and as much as $2000 \mathrm{mg}$ may be needed in patients with heavy or abnormal menstrual bleeding [50].

To help determine the optimal means of administering these higher doses, it is important to note that the degradation kinetics, and therefore the safety, of parenteral iron products are directly related to the molecular weight and stability of the iron complex [52-56].

Complexes can be generally classified as labile or robust (kinetic variability, i.e., how fast the ligands coordinated to the iron can be exchanged) and weak or strong (thermodynamic variability, i.e., how strongly the ligands are bound to the iron and thus how much energy is required to dissociate a ligand from the iron) or any intermediate state [52]. The reactivity of each complex correlates inversely with its molecular weight; larger complexes are less prone to release significant amounts of labile iron or react directly with transferrin [53, 54]. Type I complexes such as iron dextran preparations (INFeD Dexferrum) or FCM (Injectafer) have a high molecular weight and a high structural homogeneity and thereby deliver iron from the complex to transferrin in a regulated way via macrophage endocytosis and subsequent controlled export $[52,55]$. They also bind iron tightly as nonionic polynuclear iron(III) hydroxide and do not release large amounts of iron ions into the blood. Such complexes can be administered intravenously and are clinically well tolerated even when administered at high doses. For less stable iron complexes, the maximum single doses are significantly lower and the administration times are drastically longer $[54,56]$.

FCM is a stable type I polynuclear iron(III) hydroxide carbohydrate complex that prevents the partial release of iron to serum ferritin observed with IS, allowing administration of high doses, since this iron is available only via reticuloendothelial processing $[37,57,58]$. FCM can be administered as a single $750 \mathrm{mg}$ dose via a slow IV push injection over 7.5 minutes or as an IV infusion over at least 15 minutes. The second dose is administered at least 7 days later for a recommended cumulative dose of $1500 \mathrm{mg}$ iron [36]. Use of high doses reduces the number of infusions, enabling the possibility of cost reductions compared to multiple administrations [59-62].

In our study, a modified Ganzoni formula was used to calculate total iron deficits in patients from 5 clinical studies involving FCM. After analyzing each study individually, we found the overall average iron deficit in those trials to be $1531 \mathrm{mg}$, suggesting that patients having IDA of various 
etiologies may benefit from a higher cumulative dose of IV iron than what is typically administered in clinical practice utilizing most of the currently available IV iron formulations.

Using the same modified Ganzoni formula, total iron deficits were also calculated in our post hoc analyses of the 2 larger studies ( 6 and 7) involving patients with IDA secondary to numerous underlying disorders, including HUB, GI diseases, and CKD. In Study 6, the average calculated iron deficit was $1496 \mathrm{mg}$. In Study 7, the average calculated iron deficit for patients receiving either $1500 \mathrm{mg}$ IV iron, as FCM, or $1000 \mathrm{mg}$ of IS was $1352 \mathrm{mg}$. The lower figure may be due to higher baseline ferritin and TSAT values in the CKD population, as $29 \%$ of the patients did not have the $500 \mathrm{mg}$ of iron stores included in their iron deficit when it was calculated using the modified Ganzoni formula. Overall, the average calculated iron deficit in patients from Studies 6 and 7 was $1392 \mathrm{mg}$.

Data from Study 7 reinforced the benefits of higher IV iron dosing such that significantly fewer patients who received a total cumulative dose of $1500 \mathrm{mg}$ of iron required IV iron retreatment during the follow-up period (Days 5690) than those who received a total cumulative dose of $1000 \mathrm{mg}$. In addition, patients who received $1500 \mathrm{mg}$ of iron achieved their first $\mathrm{Hb}>11 \mathrm{~g} / \mathrm{dL}$ and $>12 \mathrm{~g} / \mathrm{dL}$ and $\mathrm{a} \geq 1 \mathrm{~g}$ increase in $\mathrm{Hb}$ faster than those who received $1000 \mathrm{mg}$. This finding suggests that patients given $1000 \mathrm{mg}$ may not be receiving a full repletion dose of iron compared to those given $1500 \mathrm{mg}$. Study 6 was not similarly analyzed because of confounders (i.e., small sample size and lack of consistent dosing for comparators). Despite patients in Cohort D (IV SoC) of that study having the highest mean calculated iron deficit $(1703 \mathrm{mg})$, the mean amount of iron they received was paradoxically only $812 \mathrm{mg}$. This discrepancy between deficit and treatment in patients who received IV SoC may be due, in part, to convenience factors associated with the IV SoC dosing available to the investigators during the study, as well as the lack of practical guidance for determining iron dosing requirements.

In a study that compared the Ganzoni calculated dose to a simplified dose regimen, it was found that adherence was higher with the simplified dosing and resulted in better efficacy outcomes [59]. As a result, standard of care in Europe has moved from the Ganzoni calculation to a simple dosing scheme. In the US, most of the IV iron has a simple dosing scheme and the Ganzoni formula is not utilized as frequently, our study suggests that the simplified dosing scheme most often utilized may not fully replete the iron stores of the majority of patients.

Although the results of our study suggest that a total cumulative dose of IV iron greater than $1000 \mathrm{mg}$ may be appropriate for many patients with IDA (we are aware of no similar published analyses), there are some limitations to consider. Parts of our analyses were retrospective in nature, and further prospective research will be needed to establish the long-term efficacy and safety of these higher total cumulative doses of IV iron. The population analyzed from Study 7 was limited to patients with CKD. Other etiologies of IDA may respond differently in relation to IV iron. In addition, most of the studies that evaluated the Ganzoni formula included patients with IDA resulting from a variety of disease states. Also while, to the author's knowledge significant efficacy differences between similar cumulative doses of the various IV iron products have not been demonstrated, a future prospective study comparing various doses of the same product in a homogenous patient population would remove any product or population related bias that may have occurred in our study. It may be beneficial to observe whether higher or lower total cumulative doses of the same IV iron are more efficacious for patients with specific IDA etiologies.

\section{Conclusions}

Our study suggests that a total cumulative dose of $1000 \mathrm{mg}$ of IV iron may be insufficient for iron repletion in the majority of patients with IDA and that a dose of $1500 \mathrm{mg}$ is closer to the actual iron deficit in these patients. Additionally, $1500 \mathrm{mg}$ of iron resulted in a more rapid, robust $\mathrm{Hb}$ response, allowed more patients to reach target $\mathrm{Hb}$ levels, and required a longer mean time to retreatment with additional IV iron compared to $1000 \mathrm{mg}$ of iron. Our analysis and review of the literature suggest that $1500 \mathrm{mg}$ of IV iron is more suitable for iron repletion in many patients with IDA compared to the commonly utilized dose of $1000 \mathrm{mg}$ of IV iron. Further studies to confirm appropriate dose requirements in various patient populations are warranted.

\section{Conflict of Interests}

Lawrence Tim Goodnough is a consultant for Luitpold Pharmaceuticals, Inc. Jennifer Myers was an employee of Luitpold Pharmaceuticals, Inc. Todd A. Koch is an employee of Luitpold Pharmaceuticals, Inc.

\section{Acknowledgments}

The authors would like to thank David Morris, Ph.D. degree, for statistical input during the preparation of this paper, Andy $\mathrm{He}$, PharmD, for publication management, and Aesculapius Consulting, Inc., for the editorial services.

\section{References}

[1] L. T. Goodnough, "The new age of iron: evaluation and management of iron-restricted erythropoiesis," Seminars in Hematology, vol. 46, no. 4, pp. 325-327, 2009.

[2] B. Annibale, G. Capurso, A. Chistolini et al., "Gastrointestinal causes of refractory iron deficiency anemia in patients without gastrointestinal symptoms," The American Journal of Medicine, vol. 111, no. 6, pp. 439-445, 2001.

[3] P. L. Acher, T. Al-Mishlab, M. Rahman, and T. Bates, "Irondeficiency anaemia and delay in the diagnosis of colorectal cancer," Colorectal Disease, vol. 5, no. 2, pp. 145-148, 2003.

[4] D. Raje, H. Mukhtar, A. Oshowo, and C. Ingham Clark, "What proportion of patients referred to secondary care with iron deficiency anemia have colon cancer?" Diseases of the Colon and Rectum, vol. 50, no. 8, pp. 1211-1214, 2007.

[5] M. Auerbach, J. A. Pappadakis, H. Bahrain, S. A. Auerbach, H. Ballard, and N. V. Dahl, "Safety and efficacy of rapidly 
administered (one hour) one gram of low molecular weight iron dextran (INFeD) for the treatment of iron deficient anemia," American Journal of Hematology, vol. 86, no. 10, pp. 860-862, 2011.

[6] L. T. Goodnough, E. Nemeth, and T. Ganz, "Detection, evaluation, and management of iron-restricted erythropoiesis," Blood, vol. 116, no. 23, pp. 4754-4761, 2010.

[7] M. Auerbach, H. Ballard, J. R. Trout et al., "Intravenous iron optimizes the response to recombinant human erythropoietin in cancer patients with chemotherapy-related anemia: a multicenter, open-label, randomized trial," Journal of Clinical Oncology, vol. 22, no. 7, pp. 1301-1307, 2004.

[8] M. Auerbach, "Ferumoxytol as a new, safer, easier-toadminister intravenous iron: yes or no?" The American Journal of Kidney Diseases, vol. 52, no. 5, pp. 826-829, 2008.

[9] J. Bonnar, A. Goldberg, and J. A. Smith, "Do pregnant women take their iron?" The Lancet, vol. 1, no. 7592, pp. 457-458, 1969.

[10] G. Weiss and L. T. Goodnough, "Anemia of chronic disease," The New England Journal of Medicine, vol. 352, no. 10, pp. 1011-1059, 2005.

[11] N. C. Andrews, "Anemia of inflammation: the cytokinehepcidin link," Journal of Clinical Investigation, vol. 113, no. 9, pp. 1251-1253, 2004.

[12] L. T. Goodnough and A. Shander, "Current status of pharmacologic therapies in patient blood management," Anesthesia \& Analgesia, vol. 116, no. 1, pp. 15-34, 2013.

[13] D. H. Henry, N. V. Dahl, M. Auerbach, S. Tchekmedyian, and L. R. Laufmane, "Intravenous ferric gluconate significantly improves response to epoetin alfa versus oral iron or no iron in anemic patients with cancer receiving chemotherapy," Oncologist, vol. 12, no. 2, pp. 231-242, 2007.

[14] M. Hedenus, G. Birgegard, P. Nasman et al., "Addition of intravenous iron to epoetin beta increases hemoglobin response and decreases epoetin dose requirement in anemic patients with lymphoproliferative malignancies: a randomized multicenter study," Leukemia, vol. 21, no. 4, pp. 627-632, 2007.

[15] L. Bastit, A. Vandebroek, S. Altintas et al., "Randomized, multicenter, controlled trial comparing the efficacy and safety of darbepoetin alfa administered every 3 weeks with or without intravenous iron in patients with chemotherapy-induced anemia," Journal of Clinical Oncology, vol. 26, no. 10, pp. 1611-1618, 2008.

[16] A. Gafter-Gvili, D. P. Steensma, and M. Auerbach, "Should the ASCO/ASH guidelines for the use of intravenous iron in cancerand chemotherapy-induced anemia be updated?" Journal of the National Comprehensive Cancer Network, vol. 12, no. 5, pp. 657664, 2014.

[17] J. A. Gilreath, D. D. Stenehjem, and G. M. Rodgers, "Diagnosis and treatment of cancer-related anemia," American Journal of Hematology, vol. 89, no. 2, pp. 203-212, 2014.

[18] M. Auerbach, A. S. Liang, and J. Glaspy, "Intravenous iron in chemotherapy and cancer-related anemia," Community Oncology, vol. 9, no. 9, pp. 289-295, 2012.

[19] J. D. Rizzo, M. Brouwers, P. Hurley, J. Seidenfeld, M. R. Somerfield, and S. Temin, "American Society of Clinical Oncology/American Society of Hematology clinical practice guideline update on the use of epoetin and darbepoetin in adult patients with cancer," Journal of Oncology Practice, vol. 6, no. 6, pp. 317-320, 2010.

[20] D. S. Silverberg, A. Iaina, G. Peer et al., "Intravenous iron supplementation for the treatment of the anemia of moderate to severe chronic renal failure patients not receiving dialysis," American Journal of Kidney Diseases, vol. 27, no. 2, pp. 234-238, 1996.

[21] R. S. Hillman and P. A. Henderson, "Control of marrow production by the level of iron supply," Journal of Clinical Investigation, vol. 48, no. 3, pp. 454-460, 1969.

[22] R. L. Jurado, "Iron, infections, and anemia of inflammation," Clinical Infectious Diseases, vol. 25, no. 4, pp. 888-895, 1997.

[23] K. Bishu and R. Agarwal, "Acute injury with intravenous iron and concerns regarding long-term safety," Clinical Journal of the American Society of Nephrology, supplement 1, pp. S19-S23, 2006.

[24] L. T. Goodnough, J. H. Levy, and M. F. Murphy, "Concepts of blood transfusion in adults," The Lancet, vol. 381, no. 9880, pp. 1845-1854, 2013.

[25] D. R. Spahn and L. T. Goodnough, "Alternatives to blood transfusion," The Lancet, vol. 381, no. 9880, pp. 1855-1865, 2013.

[26] L. T. Goodnough, "Blood management: transfusion medicine comes of age," The Lancet, vol. 381, no. 9880, pp. 1791-1792, 2013.

[27] A. Shander, R. K. Spence, and M. Auerbach, "Can intravenous iron therapy meet the unmet needs created by the new restrictions on erythropoietic stimulating agents?: report from the Society for the Advancement of Blood Management 2008 Annual Meeting," Transfusion, vol. 50, no. 3, pp. 719-732, 2010.

[28] M. Auerbach, L. T. Goodnough, D. Picard, and A. Maniatis, "The role of intravenous iron in anemia management and transfusion avoidance," Transfusion, vol. 48, no. 5, pp. 988-1000, 2008.

[29] G. M. Chertow, P. D. Mason, O. Vaage-Nilsen, and J. Ahlmén, "Update on adverse drug events associated with parenteral iron," Nephrology Dialysis Transplantation, vol. 21, no. 2, pp. 378-382, 2006.

[30] Dexferrum [package insert], American Regent, Shirley, NY, USA, 2008.

[31] INFeD, Package Insert, Watson Pharma, Morristown, NJ, USA, 2009.

[32] A. M. Ganzoni, "Intravenous iron-dextran: therapeutic and experimental possibilities," Schweizerische Medizinische Wochenschrift, vol. 100, no. 7, pp. 301-303, 1970.

[33] American Regent, Venofer [Package Insert], American Regent, Shirley, NY, USA, 2012.

[34] Ferrlecit, Package Insert, Sanofi-Aventis US, Bridgewater, NJ, USA, 2011.

[35] Feraheme [package insert], AMAG Pharmaceuticals, Lexington, Mass, USA, 2015.

[36] American Regent, Injectafer [Package Insert], American Regent, Shirley, NY, USA, 2013.

[37] S. Kulnigg, S. Stoinov, V. Simanenkov et al., "A novel intravenous iron formulation for treatment of anemia in inflammatory bowel disease: the ferric carboxymaltose (FERINJECT) randomized controlled trial," The American Journal of Gastroenterology, vol. 103, no. 5, pp. 1182-1192, 2008.

[38] D. B. van Wyck, M. G. Martens, M. H. Seid, J. B. Baker, and A. Mangione, "Intravenous ferric carboxymaltose compared with oral iron in the treatment of postpartum anemia: a randomized controlled trial," Obstetrics and Gynecology, vol. 110, no. 2, pp. 267-278, 2007.

[39] D. B. van Wyck, A. Mangione, J. Morrison, P. E. Hadley, J. A. Jehle, and L. T. Goodnough, "Large-dose intravenous ferric carboxymaltose injection for iron deficiency anemia in heavy 
uterine bleeding: a randomized, controlled trial," Transfusion, vol. 49, no. 12, pp. 2719-2728, 2009.

[40] M. H. Seid, R. J. Derman, J. B. Baker, W. Banach, C. Goldberg, and R. Rogers, "Ferric carboxymaltose injection in the treatment of postpartum iron deficiency anemia: a randomized controlled clinical trial," American Journal of Obstetrics \& Gynecology, vol. 199, no. 4, pp. 435.e1-435.e7, 2008.

[41] C. F. Barish, T. Koch, A. Butcher, D. Morris, and D. B. Bregman, "Safety and efficacy of intravenous ferric carboxymaltose (750 mg) in the treatment of iron deficiency anemia: two randomized, controlled trials," Anemia, vol. 2012, Article ID 172104, 9 pages, 2012.

[42] I. Hussain, J. Bhoyroo, A. Butcher, T. A. Koch, A. He, and D. B. Bregman, "Direct comparison of the safety and efficacy of ferric carboxymaltose versus iron dextran in patients with iron deficiency anemia," Anemia, vol. 2013, Article ID 169107, 10 pages, 2013.

[43] J. E. Onken, D. B. Bregman, R. A. Harrington et al., "A multicenter, randomized, active-controlled study to investigate the efficacy and safety of intravenous ferric carboxymaltose in patients with iron deficiency anemia," Transfusion, vol. 54, no. 2, pp. 306-315, 2014.

[44] J. E. Onken, D. B. Bregman, R. A. Harrington et al., "Ferric carboxymaltose in patients with iron-deficiency anemia and impaired renal function: the REPAIR-IDA trial," Nephrology Dialysis Transplantation, vol. 29, no. 4, pp. 833-842, 2014.

[45] National Kidney Foundation. KDOQI, "Clinical practice guidelines and clinical practice recommendations for anemia in chronic kidney disease," American Journal of Kidney Diseases, vol. 47, supplement 3, pp. S1-S145, 2006.

[46] Kidney Disease: Improving Global Outcomes (KDIGO) Anemia Work Group, "KDIGO clinical practice guideline for anemia in chronic kidney disease," Kidney International Supplements, vol. 2, no. 4, pp. S279-S335, 2012.

[47] National Comprehensive Cancer Network (NCCN), Clinical Practice Guidelines in Oncology. Cancer- and ChemotherapyInduced Anemia. Version 2, NCCN, 2015.

[48] M. Aapro, A. Österborg, P. Gascón, H. Ludwig, and Y. Beguin, "Prevalence and management of cancer-related anaemia, iron deficiency and the specific role of I.V. iron," Annals of Oncology, vol. 23, no. 8, pp. 1954-1962, 2012.

[49] C. Gasche, A. Berstad, R. Befrits et al., "Guidelines on the diagnosis and management of iron deficiency and anemia in inflammatory bowel diseases," Inflammatory Bowel Diseases, vol. 13, no. 12, pp. 1545-1553, 2007.

[50] D. Gozzard, "When is high-dose intravenous iron repletion needed? Assessing new treatment options," Drug Design, Development and Therapy, no. 5, pp. 51-60, 2011.

[51] P. Geisser and V. Rumyantsev, "Pharmacodynamics and safety of ferric carboxymaltose: a multiple-dose study in patients with iron-deficiency anaemia secondary to a gastrointestinal disorder," Arzneimittelforschung, vol. 60, no. 6, pp. 373-385, 2010.

[52] R. R. Crichton, B. Danielson, and P. Geisser, Iron Therapy with Special Emphasis on Intravenous Administration, UNI-MED, Bremen, Germany, 4th edition, 2008.

[53] B. G. Danielson, "Structure, chemistry, and pharmacokinetics of intravenous iron agents," Journal of the American Society of Nephrology, vol. 15, no. 2, pp. S93-S98, 2004.

[54] P. Geisser, M. Baer, and E. Schaub, "Structure/histotoxicity relationship of parenteral iron preparations," Drug Research, vol. 42, no. 12, pp. 1439-1452, 1992.
[55] S. Beshara, H. Lundqvist, J. Sundin et al., "Pharmacokinetics and red cell utilization of iron(III) hydroxide-sucrose complex in anaemic patients: a study using positron emission tomography," British Journal of Haematology, vol. 104, no. 2, pp. 296-302, 1999.

[56] P. Geisser and S. Burckhardt, "The pharmacokinetics and pharmacodynamics of iron preparations," Pharmaceutics, vol. 3, no. 1, pp. 12-33, 2011.

[57] M. Malone, C. Barish, A. He, and D. Bregman, "Comparative review of the safety and efficacy of ferric carboxymaltose versus standard medical care for the treatment of iron deficiency anemia in bariatric and gastric surgery patients," Obesity Surgery, vol. 23, no. 9, pp. 1413-1420, 2013.

[58] K. A. Lyseng-Williamson and G. M. Keating, "Ferric carboxymaltose: a review of its use in iron-deficiency anaemia," Drugs, vol. 69, no. 6, pp. 739-756, 2009.

[59] R. Evstatiev, P. Marteau, T. Iqbal et al., "FERGIcor, a randomized controlled trial on ferric carboxymaltose for iron deficiency anemia in inflammatory bowel disease," Gastroenterology, vol. 141, no. 3, pp. 846.e2-853.e2, 2011.

[60] X. Calvet, M. À. Ruíz, A. Dosal et al., "Cost-minimization analysis favours intravenous ferric carboxymaltose over ferric sucrose for the ambulatory treatment of severe iron deficiency," PLoS ONE, vol. 7, no. 9, Article ID e45604, 2012.

[61] F. Gomollón and J. P. Gisbert, "Current management of iron deficiency anemia in inflammatory bowel diseases: a practical guide," Drugs, vol. 73, no. 16, pp. 1761-1770, 2013.

[62] A. A. Khalafallah and A. E. Dennis, "Iron deficiency anaemia in pregnancy and postpartum: pathophysiology and effect of oral versus intravenous iron therapy," Journal of Pregnancy, vol. 2012, Article ID 630519, 10 pages, 2012. 


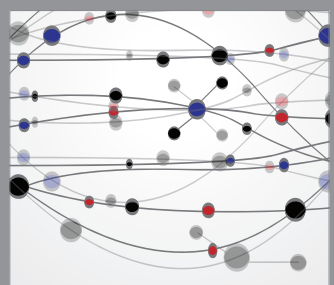

The Scientific World Journal
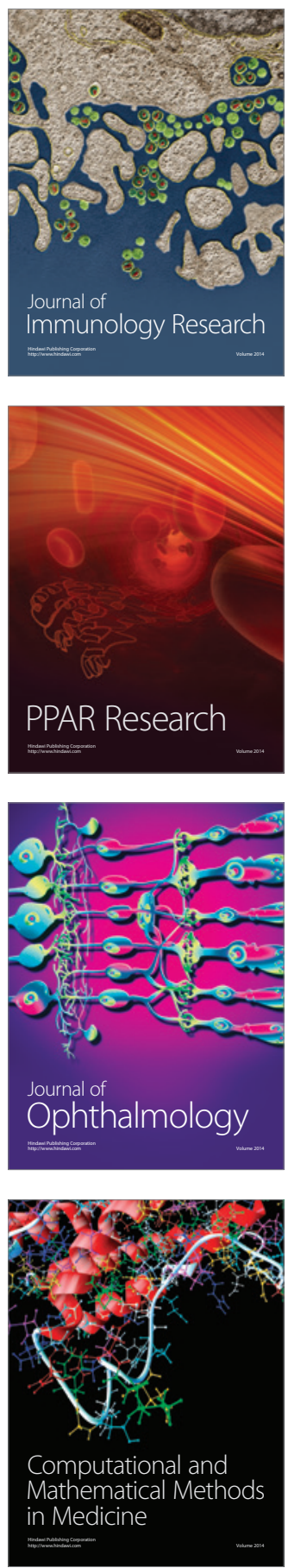

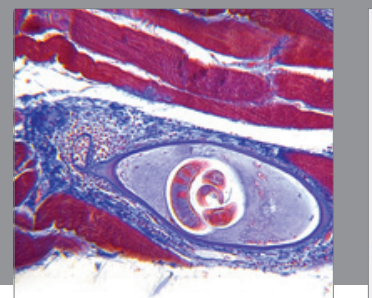

Gastroenterology

Research and Practice
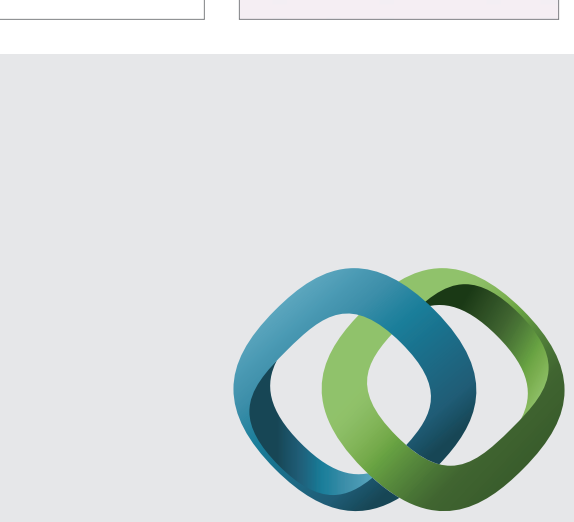

\section{Hindawi}

Submit your manuscripts at

http://www.hindawi.com
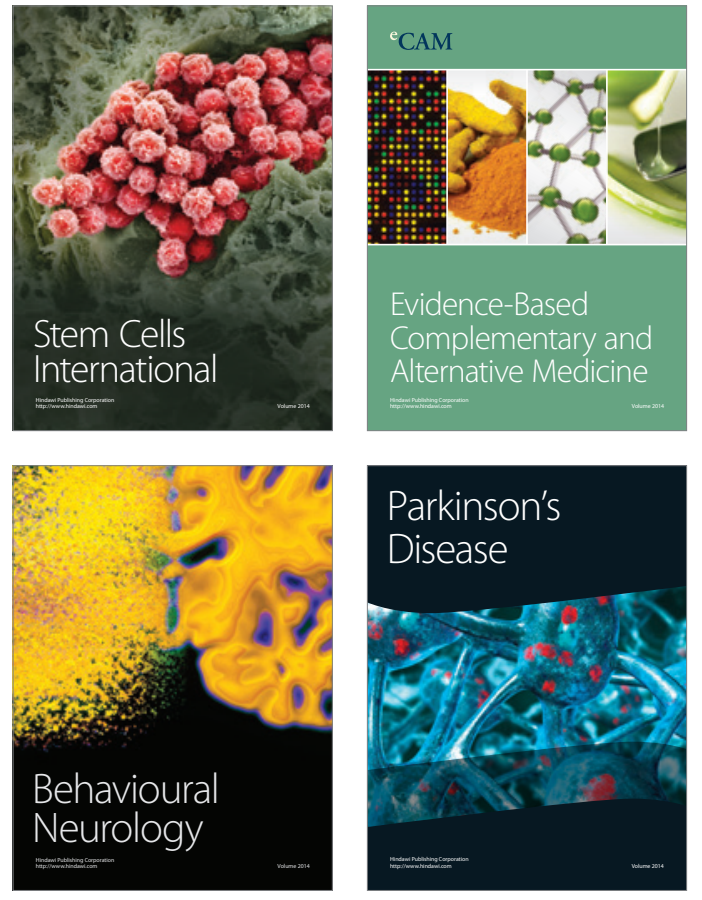
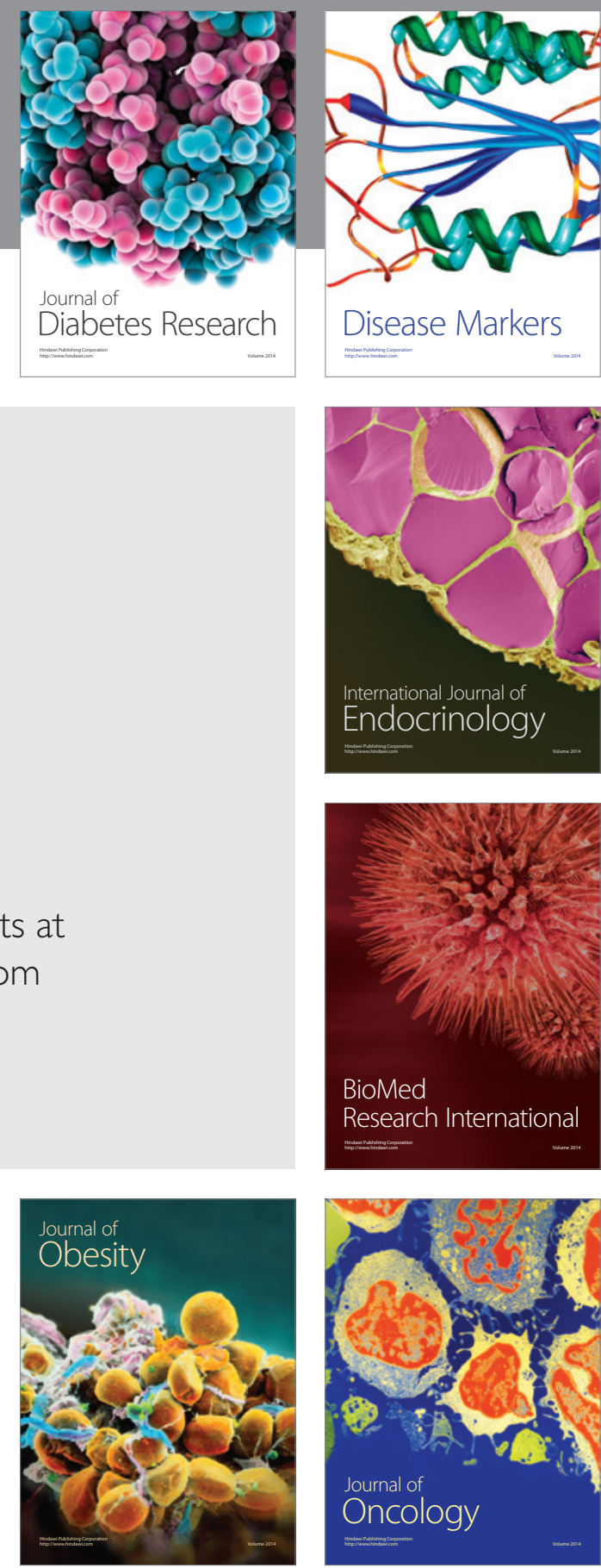

Disease Markers
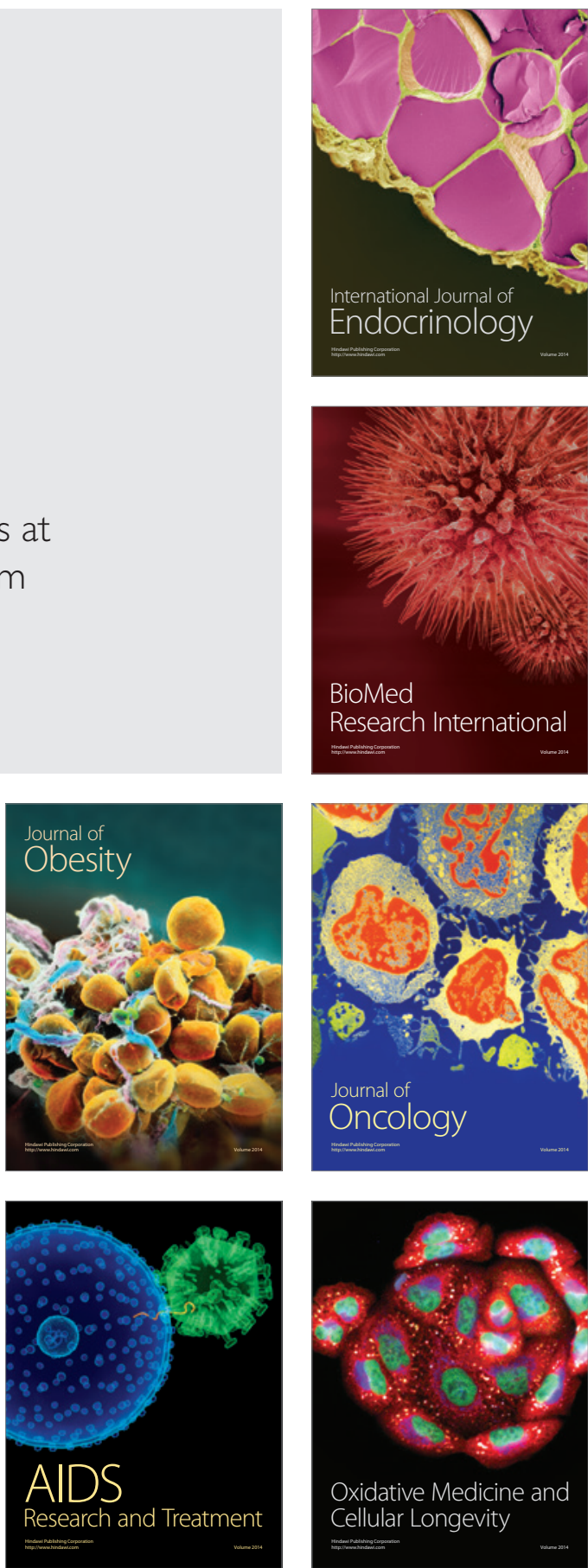